\title{
Airflow field simulation model building and application for aerobic compost using CFD
}

\author{
Qiongyi Cheng, Haibo Meng, Haibin Zhou, Yujun Shen*, Hongsheng Cheng, Jingtao Ding, \\ Shihao Zhao, Shance Hou \\ (Academy of Agricultural Planning and Engineering, Key Laboratory of Technologies and Models for Cyclic Utilization from \\ Agricultural Resources, Ministry of Agriculture and Rural Affairs, Beijing 100125, China)
}

\begin{abstract}
Composting is a suitable low-cost strategy to transform animal waste into a stabilized end product, and the airflow field in the pile affects the fermentation states. For piles in the aeration weak zone, anaerobic fermentation may happen as the lack of oxygen. While in practice, due to the extremely low speed and harsh condition, the airflow field was scarcely researched. This study adopted Computational Fluid Dynamics (CFD) to investigate the airflow field in the compost pile. A three-dimensional CFD model was built; the compost pile in this model was simplified as porous media; unstructured mesh was adopted to discretize the geometric model; standard $k-\varepsilon$ model and SIMPLE scheme were employed for numerical methods. The CFD model was validated with the field experiment in the cooling period. Then the model was applied to research the airflow field in the pile with increased pipe diameter. Results showed that it was feasible to investigate the airflow field in the pile with CFD. For boundary conditions in the CFD model, treating the compost pile as a homogeneous porous media is reasonable. The CFD model was successfully validated by the field measurement (the average relative difference between the simulated and measured air speed was within 10\%). Airflow in the existing compost pile showed nonuniform distribution with stagnation and vortex zones; the turbulence intensities were 3.57 and 1.43 for the airflow in the pile and the reactor, respectively. When pipe diameter increased, the airflow distribution uniformity in the pile was improved significantly. With diameter raising to $0.04 \mathrm{~m}$, the turbulence intensity decreased to 1.54 and 0.42 for the airflow in the pile and the reactor, respectively. The CFD model developed in this research can provide qualitative and quantitative analyses of the airflow field in compost piles, and can be a theoretical basis for the aeration system design.
\end{abstract}

Keywords: CFD, model building, compost, airflow field, pile

DOI: $10.25165 /$ j.ijabe.20211404.6087

Citation: Cheng Q Y, Meng H B, Zhou H B, Shen Y J, Cheng H S, Ding J T, et al. Airflow field simulation model building and application for aerobic compost using CFD. Int J Agric \& Biol Eng, 2021; 14(4): 245-254.

\section{Introduction}

The waste produced by livestock and poultry production was approximately 3.8 billion $\mathrm{t}$ in China, while the effective utilization ratio was merely $64 \%$ in $2018^{[1]}$. The waste that was not properly treated can lead to hygiene hazards, odor pollution, and water contamination caused by the leaching of pollutants. Concerning this issue, compost was increasingly considered as a suitable low-cost strategy. It can transform the surplus of manure into stabilized and sanitized end product for agriculture, which was beneficial to increasing the nutrient status ${ }^{[2]}$ and amending the internal structure of the soil ${ }^{[3]}$. Composting was widely adopted for organic waste disposal worldwide. For instance, in the UK in

\section{Received date: 2020-08-18 Accepted date: 2021-04-15}

Biographies: Qiongyi Cheng, $\mathrm{PhD}$, research interest: environment control, waste management, Email: qiongyicheng@cau.edu.cn; Haibo Meng, PhD, research interest: waste management, compost, Email: newmhb7209@163.com; Haibin Zhou, PhD, research interest: waste disposal, composting process management, Email: nxzhb66@163.com; Hongsheng Cheng, PhD, research interest: compost equipment research and development, Email: steerfeng@, 163.com; Jingtao Ding, $\mathrm{PhD}$, research interest: waste disposal, Email: dingjingtao@163.com; Shihao Zhao, Master, research interest: compost equipment research and development, Email: Zsh980924@163.com; Shance Hou, Master, research interest: compost equipment research and development, Email: hou_shance@163.com.

*Corresponding author: Yujun Shen, $\mathrm{PhD}$, research interest: waste disposal, composting process control. Academy of Agricultural Planning and Engineering, Ministry of Agriculture and Rural Affairs, Beijing 100125, China. Email: shenyj09b@163.com.
2012, 0.39 million tons of compost end product were produced by 30 biological treatment facilities ${ }^{[4]}$. In the USA, nearly $36 \%$ of solid wastes were disposed of through compost ${ }^{[5]}$. Furthermore, the production of commercial compost in China had been rapidly increased in the last few decades, compared to 2011, it was increased by $48 \%$ in 2016, with approximately 2.14 million $\mathrm{t}^{[6]}$.

For compost, since the inlet air can provide oxygen for the biological process and remove excess moisture from the compost pile ${ }^{[7]}$, the airflow field in the pile is vital to the composting efficiency and the end product quality ${ }^{[8]}$. Moreover, the airflow field determines the oxygen supply uniformity. The suitable air speed and uniform airflow distribution could result in the increasing degradation rate of the organic matter, decreasing nitrogen loss as well as the greenhouse gas (GHG) emissions, and the higher quality of the end product ${ }^{[9]}$. Nonetheless, due to the extremely low speed and harsh conditions in the pile, scarce studies are performed to quantify the air speed and spatial distribution of airflow in $\mathrm{it}^{[10]}$. Hence it is critical to building a simulation model that could analyze the airflow field in the pile.

In practice, the compost with positive aeration has been in widespread use as a short fermentation period and excellent end-product quality. Numerous studies have illustrated that in this system, the aeration technology, which includes the aeration volume and pipe system, is vitally important to the airflow field. The aeration volume for different compost substrates has been extensively researched ${ }^{[11,12]}$, while the effect of different pipe design parameters on airflow fields in compost piles is rarely 
studied. Actually, the pipe design mostly bases on empirical guidelines and lacks a sound theoretical basis ${ }^{[13]}$. In a large-scale aerobic composting reactor, due to the immense volume of compost material and poorly designed aeration system, an anaerobic fermentation easily happens somewhere ${ }^{[14]}$. Since the appropriate pipe design is essential to assure uniform airflow distribution and energy-saving ${ }^{[15]}$, fully achieving the knowledge of the airflow field in the compost pile is indispensable.

Nowadays, Computational Fluid Dynamics (CFD) has become a robust design tool and has been widely adopted to research the flow field. It could overcome most drawbacks of the field measurement, including high cost, limited measurement points, and incomplete results caused by different samples selection. With $\mathrm{CFD}$, it is more convenient to obtain all relevant environmental information within the simulation zone and the airflow pattern could be analyzed quantitatively and qualitatively. Likewise, CFD was commonly used in the research and optimization of the airflow field in the civil architecture as well as the waste disposal, like optimization of the inlet position for the natural ventilated-building ${ }^{[16]}$; evaluating the performance of the activated sludge system ${ }^{[17,18]}$; exploring the flow field in the sludge management device ${ }^{[19,20]}$; investigating the airflow pattern in the biogas digester with the optimized shape of the stirrer ${ }^{[21]}$; comparing airflow conditions under the varied mixing parameters for the fermentation system ${ }^{[22,23]}$. However, the application of CFD in analyzing the airflow field in the compost pile is rare.

For model building in CFD, simplification has been extensively used on account of computing power and time-saving. Porous media has always been served as a reasonable simplification approach for simulating flows through complex geometries. Seyedpour et al. ${ }^{[24]}$ adopted it to simplify soil when simulating the contaminant transport; Olatunde et al. ${ }^{[25]}$ treated grain as porous media when calculating airflow in the rice silos; Qi et al. ${ }^{[26]}$ regarded sand bed filter as porous media when researching the hydraulic performance within it; Kichah ${ }^{[27]}$ considered the crop as porous media when analyzing the microclimate inside a greenhouse canopy; $\mathrm{Wu}$ and $\mathrm{Cheng}^{[28,29]}$ treated the animal occupied zone as porous media. Consequently, due to the complex structure of the pile and barely to model in actual geometry ${ }^{[30]}$, this study also simplifies pile and additional polyporous accessories into porous media, instead of real geometry modeling. Furthermore, a variety of issues affect the accuracy of simulation results, like simplification method, selection of turbulence models, differencing schemes, grid convergence study, convergence criteria, etc ${ }^{[31-33]}$. To ensure the accuracy of simulations, validation and verification of the simulation model were indispensable. In this study, as the physicochemical property of pile at cooling period was relative stable during the whole compost process ${ }^{[34]}$, the CFD model was validated with the field experiment at the cooling period.
In order to obtain the boundary conditions and validate the accuracy of the simulation model, a compost experiment was conducted. Meanwhile, to build a model that could simulate the airflow in the pile, the mesh, numerical methods, and boundary conditions of the model were researched. Lastly, the CFD model was applied to research the aeration performance of compost piles with increased pipe diameter. The aim of the present study is to make contributions to evaluating the airflow field in the compost pile. The objectives of this study are to 1) research the feasibility to simplify piles as homogeneous porous media; 2) develop a three-dimensional CFD model to simulate airflow field in piles; 3 ) apply the model to simulate airflow field in piles with increased aeration pipe diameter.

\section{Materials and methods}

\subsection{Compost experiment}

The experiment was conducted in a compost reactor. The reactor was located at the Shuangqiao campus of the Academy of Agricultural Engineering Planning and Design, Ministry of Agriculture and Rural Affairs, Beijing, China (Figure 1a). The volume was $1400 \mathrm{~L}$, with dimensions of $4.35 \mathrm{~m} \times 1 \mathrm{~m} \times 1.1 \mathrm{~m}$ (length $\times$ width $\times$ height). For the sake of description, a direction parallel to the length, width, and height of the reactor was labeled as $x, y$, and $z$ directions, respectively. The reactor was divided into three zones, including maintenance, compost, and aeration zone. The maintenance zone was at the upper part of the reactor, which was used for daily maintenance of the facility. Beneath it was an aeration and compost zone, to decrease the dissipation rate of compost thermogenesis, an insulation layer of $0.2 \mathrm{~m}$ was added to the envelope. In the compost zone, to monitor the fermentation condition of the pile, three temperature sensors (YCSBWZ-2088) were placed along the $x$-direction of the reactor and $250 \mathrm{~mm}$ high from the bottom. Two stirring plates were installed to accelerate the evaporation rate and ensure the full fermentation of the pile. The aeration and compost zone were separated by a perforated chain plate with a thickness of $0.002 \mathrm{~m}$. Airflow entered the compost zone through holes in the pipe, and provided oxygen for the aerobic fermentation, finally exhausted through the outlet (Figure 1b). The diameter of holes in the plate was $0.004 \mathrm{~m}$, the minimum distance between the center points of holes in the same row was $0.008 \mathrm{~m}$, and for holes in the adjacent row were $0.006 \mathrm{~m}$ and $0.004 \mathrm{~m}$ in $x$ and $y$ directions, respectively. The aeration zone was at the bottom of the reactor, with dimensions of $4 \mathrm{~m} \times 0.6 \mathrm{~m} \times 0.29 \mathrm{~m}($ length $\times$ width $\times$ height $)$. The main pipe with a diameter of $0.042 \mathrm{~m}$ and five branch pipes with a diameter of $0.013 \mathrm{~m}$ were installed in it, and the distance between adjacent branch pipes was $0.6 \mathrm{~m}$. Two rows of staggered arranged holes were opened in the pipe, the projection angle of holes on cross section was $60^{\circ}$; the spacing between the adjacent holes was $0.025 \mathrm{~m}$; the number of holes in each branch pipe was 25 .

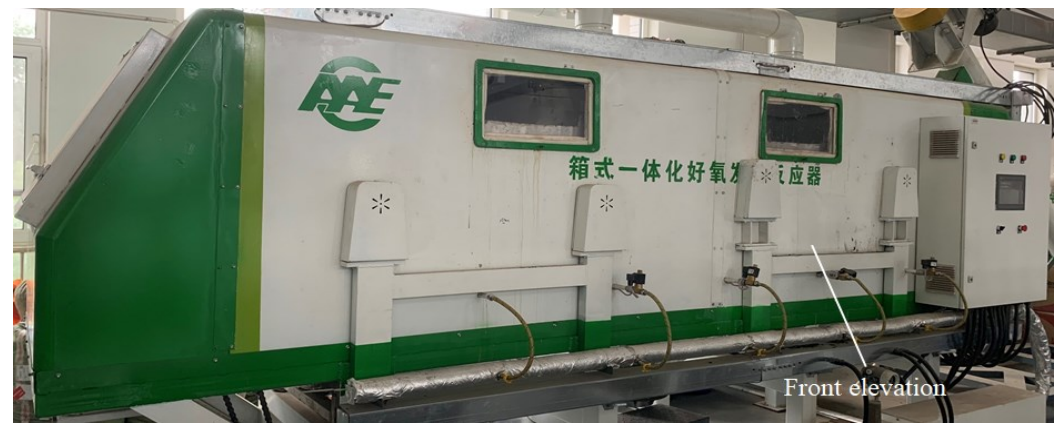

a. Outline of reactor 


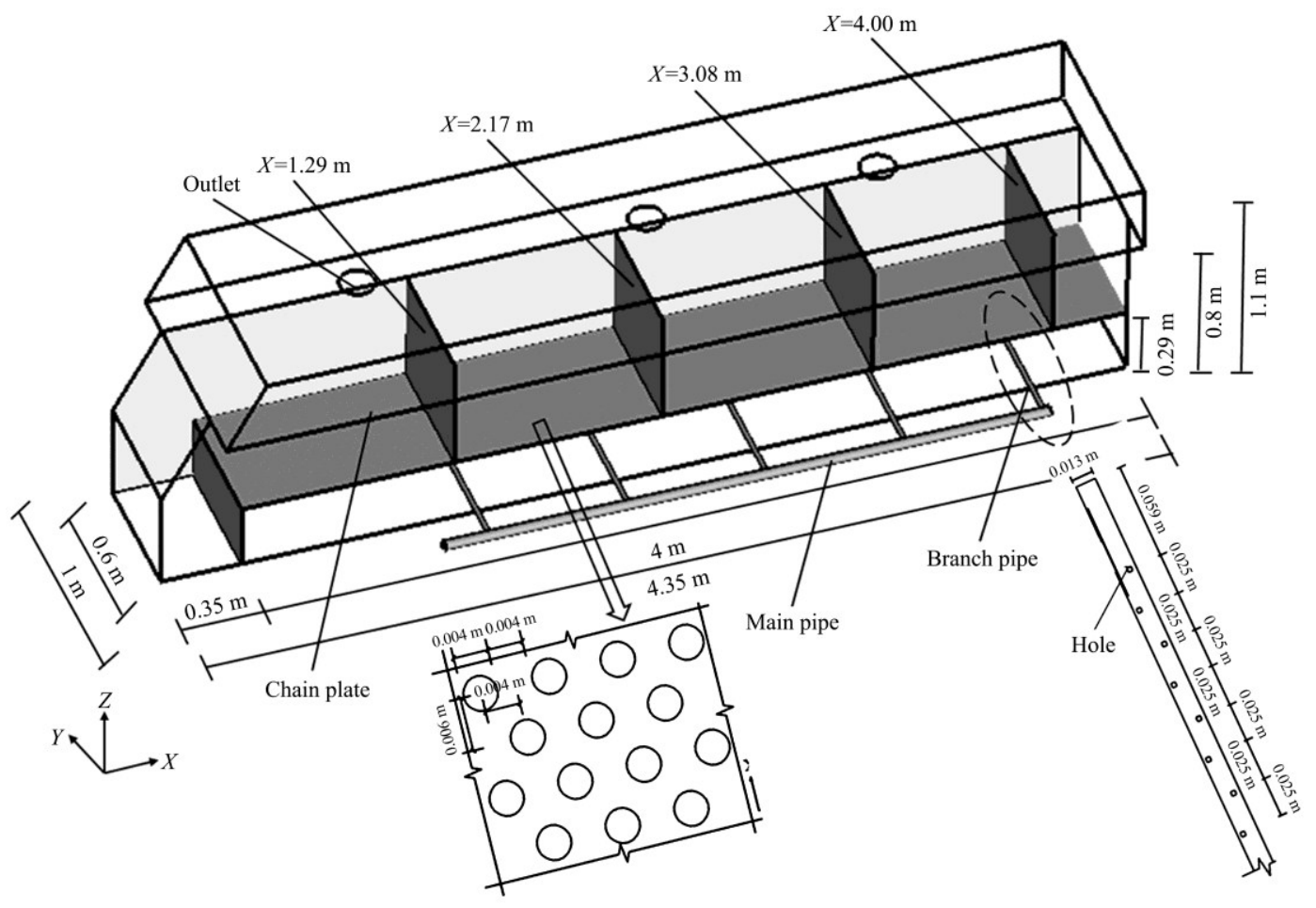

b. Interior structure of in-vessel compost reactor

Figure 1 Schematics diagram of the in-vessel reactor, chain plate and branch pipe

The compost experiment was carried out with pig manure and straw at a mass ratio of 15:4, and the length of the straw was approximately $1 \mathrm{~cm}$. The height of the compost pile was $40 \mathrm{~cm}$, and the initial humidity was $60 \%$. To ensure aerobic fermentation, the aeration volume was $32.5 \mathrm{~m}^{3} / \mathrm{h}^{[8]}$ with an intermittent aeration mode that was set as $5 \mathrm{~min}$ aeration and $25 \mathrm{~min}$ pause. Stirring plates operated every two days for $5 \mathrm{~min}$. The whole experiment lasted $15 \mathrm{~d}$. After the $1 \mathrm{st}$ day, the internal temperature of the compost pile increased to $51^{\circ} \mathrm{C}$ and rose to $60^{\circ} \mathrm{C}$ after $3 \mathrm{rd}$ day, then temperature remained above $60^{\circ} \mathrm{C}$ until 7 th day, thenceforth, it decreased to $30^{\circ} \mathrm{C}$ until the end of the experiment.

\subsection{Model building}

\subsubsection{Model geometry and mesh}

The geometry of the reactor model was the same as the in-vessel compost reactor, and the model dimension was in 1:1 scale to it. The model was built in a Cartesian coordinate system. The dimension in $x$-direction was from 0 to $4.35 \mathrm{~m}$; in $y$-direction was from 0 to $1 \mathrm{~m}$; in $z$-direction was from 0 to $1.1 \mathrm{~m}$. The model was discretized by unstructured mesh, the maximum size for the pipe was $0.003 \mathrm{~m}$; for the surface of the reactor was $0.03 \mathrm{~m}$; for inlet and outlet was $0.01 \mathrm{~m}$. To ensure the accuracy of the results simulated by the model, a grid-sensitivity analysis was performed, and three levels of mesh with the cell numbers 13462142 , 7812996 and 5123448 were compared on the basis of average simulated velocities in 9 points with a pile. The relative differences of average velocities between coarse, medium mesh with fine mesh were $8.5 \%$ and $4.3 \%$, respectively. Therefore the medium mesh was employed in further simulations.

\subsubsection{Numerical methods}

Since the standard k- $\varepsilon$ model was commonly adopted to research the airflow field in the enclosed space ${ }^{[35]}$, this study also adopted it. The SIMPLE scheme was employed to couple the pressure and velocity. The second order upwind spatial discretization method was selected for momentum, turbulent kinetic energy, and turbulent dissipation rate.

\subsubsection{Boundary conditions}

The chain plate and the compost pile were treated as porous media for the case of the reactor with a pile. While without pile, the only plate was simplified into porous media, and the others were the same. Boundary conditions for simulation are shown in Table 1. The calculation of resistance coefficients of the pile and plate were illustrated below.

Table 1 Boundary conditions

\begin{tabular}{ll}
\hline \multicolumn{1}{c}{ Items } & \multicolumn{1}{c}{ Boundary conditions } \\
\hline Inlet & Velocity inlet, $v=6.53 \mathrm{~m} / \mathrm{s}$ \\
Outlet & Pressure outlet, gauge pressure 0 \\
Envelop of reactor, wall of pipe & No slip wall \\
Hole in pipe & Interior \\
Chain plate & $\begin{array}{l}\text { Porous jump, porous media with thickness } \\
\text { of } 0.002 \mathrm{~m}\end{array}$ \\
Pile & Porous media \\
\hline
\end{tabular}

1) The resistance coefficients of the compost pile

The resistance coefficients of the compost pile were obtained by empirical equations, physical parameters of the pile used in empirical equations were achieved through lab experiments.

a. Empirical equations

Resistance coefficients of the pile were calculated by Ergun equation:

$$
\begin{gathered}
\alpha=\frac{D_{\mathrm{p}}{ }^{2}}{150} \frac{\varepsilon^{3}}{(1-\varepsilon)^{2}} \\
C_{V \mathrm{p}}=\frac{1}{\alpha} \\
C_{I \mathrm{p}}=\frac{3.5}{D_{\mathrm{p}}} \frac{(1-\varepsilon)}{\varepsilon^{3}}
\end{gathered}
$$

where, $\alpha$ is permeability, $\mathrm{m}^{2} ; D_{\mathrm{p}}$ is mean particle diameter, $\mathrm{m} ; \varepsilon$ is void fraction, $\% ; C_{V \mathrm{p}}$ is viscous resistance coefficient of the pile, $\mathrm{m}^{-2} ; C_{I \mathrm{p}}$ is inertial resistance coefficient of the pile, $\mathrm{m}^{-1}$.

Unit weight and specific gravity of pile were calculated by 
cutting-ring and pycnometry method, respectively. The void fraction of the pile was obtained with the following equations:

$$
\begin{gathered}
\gamma_{P}=\frac{M_{c p}-M_{c}}{V_{c}} \\
G_{p}=\frac{M_{b p}-M_{b}}{M_{b y}+M_{b \mathrm{p}}-M_{b}-M_{b y p}} G_{y T} \\
G_{\mathrm{y} T}=\frac{M_{b y}-M_{b}}{V_{p} \rho_{w}} \\
\varepsilon=\left(1-\gamma_{p} / G_{p} \rho_{w}\right) \times 100
\end{gathered}
$$

where, $\gamma_{P}$ is the unit weight of pile, $\mathrm{g} / \mathrm{cm}^{3} ; \rho_{\mathrm{w}}$ is the density of purified water, $\mathrm{g} / \mathrm{cm}^{3} ; G_{p}$ is the specific gravity of pile; $M_{c p}$ is the total weight of cutting ring and dried pile, $\mathrm{g} ; M_{c}$ is the weight of cutting ring, $\mathrm{g} ; V_{c}$ is the volume of cutting ring, $\mathrm{cm}^{3} ; M_{b p}$ is the total weight of pycnometer and dried pile, $\mathrm{g} ; M_{b}$ is the weight of pycnometer, g; $M_{b y}$ is the total weight of pycnometer and neutral liquids after placed in a vacuum saturation device for $4 \mathrm{~h}, \mathrm{~g} ; M_{b y p}$ is the total weight of pycnometer, neutral liquids and dried pile after placed in a vacuum saturation device for $4 \mathrm{~h}, \mathrm{~g} ; G_{\mathrm{y} T}$ is the specific gravity of neutral liquids at $T^{\circ} \mathrm{C} ; V_{p}$ is the volume of pycnometer, $\mathrm{cm}^{3}$.

b. Lab experiment for physical parameters of the compost pile

After the composting experiment was carried out for $192 \mathrm{~h}$, the void fraction and particle diameter of piles were measured. 36 samples were collected by cutting ring. Sampling points were at planes of $x=1.29,2.17,3.08$ and $4.00 \mathrm{~m}$ (Figure 1b), which were $0.3,0.5$ and $0.7 \mathrm{~m}$ away from front elevation $(y=0.3,0.5$ and $0.7 \mathrm{~m})$, and height were $0.4,0.5$ and $0.6 \mathrm{~m}(z=0.4,0.5$ and $0.6 \mathrm{~m})$, respectively. The measurement methods of unit weight, the specific gravity of pile and mean particle diameter were illustrated below. Results were averaged for the calculation.

Unit weight of pile: Cleaned and dried the cutting ring with electronic scales (JA2003Mc) and then weighted. The samples were acquired with the cutting ring of $100 \mathrm{~cm}^{3}$, and dried by an oven (BPG-9140A) at $105^{\circ} \mathrm{C}$ for $24 \mathrm{~h}$ to a constant weight.

The specific gravity of pile: Cleaned and dried the volumetric flask of $100 \mathrm{~mL}$ and then weighted. The dried pile was placed in the volumetric flask. Kerosene was injected into an empty volumetric bottle and volumetric bottle with a pile, respectively. Then bottles were placed into a vacuum saturation device (ZK-270) that had a pressure difference of about $0.1 \mathrm{MPa}$ with atmosphere. After $4 \mathrm{~h}$ until no bubbles emerged, vacuumed kerosene was added into two volumetric bottles to $100 \mathrm{~mL}$, of which one was only filled with kerosene, and the other one was filled with the pile and kerosene, respectively.

Mean particle diameter: The varied diameter of the pile was divided by screens into 7 levels using a sieve shaker (ZBSX-92A) with a sieve time of $15 \mathrm{~min}$. Since the maximum particle size was less than $30.00 \mathrm{~mm}$, the sizes of the screens chose in this study were $0.25 \mathrm{~mm}, 0.50 \mathrm{~mm}, 1.00 \mathrm{~mm}, 2.00 \mathrm{~mm}, 5.00 \mathrm{~mm}, 10.00 \mathrm{~mm}$, and $20.00 \mathrm{~mm}$. The equation for calculation of mean particle diameter was shown below:

$$
D_{\mathrm{p}}=\exp \left[\frac{\sum_{i} n_{i} \ln D_{i}}{\sum_{i} n_{i}}\right]
$$

where, $D_{\mathrm{p}}$ is the mean particle diameter of pile, $\mathrm{mm} ; n_{i}$ is class frequency; $D_{i}$ is the midpoint of the $i$-th interval, $\mathrm{mm}^{[36]}$.

2) The resistance coefficients of chain plate

The resistance coefficients of the chain plate were achieved by CFD simulation, which placed the plate in a virtual wind tunnel and simulated the pressure drops under different inlet velocities.

a) Equation for resistance coefficients

The resistance coefficients were gained by regression between pressure drops and inlet velocities:

$$
\Delta P_{z} / L_{z}=-\left(C_{V z} \mu v_{z}+C_{I z} \frac{1}{2} \rho\left|v_{z}\right| v_{z}\right)
$$

where, $\Delta P_{\mathrm{z}} / L_{z}$ is the pressure drop per unit length in $z$-direction, $\mathrm{Pa} / \mathrm{m} ; C_{V z}$ is the viscous resistance coefficient of the plate in $z$-direction, $\mathrm{m}^{-2} ; C_{I z}$ is the inertial resistance coefficient of the plate in $z$-direction, $\mathrm{m}^{-1} ; v_{z}$ is the inlet air velocity in $z$-direction, $\mathrm{m} / \mathrm{s} ; \mu$ is the dynamic viscosity of air, $\mathrm{N} \cdot \mathrm{s} / \mathrm{m}^{2} ; \rho$ is the air density, $\mathrm{kg} / \mathrm{m}^{3}$.

b) Geometry of virtual wind tunnel and mesh

A piece of chain plate with dimensions of $0.03 \mathrm{~m} \times 0.025 \mathrm{~m} \times$ $0.002 \mathrm{~m}$ was selected for the simulation. A virtual wind tunnel shown in Figure 2a was built, with the length of $0.08 \mathrm{~m}$ and $0.15 \mathrm{~m}$, for the inlet and outlet, respectively. The mesh was generated in ICEM CFD (ver17.0, ANSYS Inc., Pennsylvania, USA), which was hybrid with untrusted tetrahedral grids in plate zone $(0.012 \mathrm{~m} \times$ $0.025 \mathrm{~m} \times 0.030 \mathrm{~m}$, the outline is shown in Figure $2 \mathrm{~b}$ ) and structured hexahedral grids in the wind tunnel zone. The differently shaped grids were connected with an interface. A grid independence test was implemented with fine (3 125623 cells), medium (1 886560 ), and coarse $(1027258)$ meshes. The relative differences of pressure drop in the front and back of the plate zone between the coarse, medium, and fine mesh were $5.1 \%$ and $3.2 \%$, respectively. Hence the medium mesh was adopted for the following calculations.

c) Numerical methods and boundary conditions

The numerical methods adopted were the same as it in the simulation model of airflow in the compost pile above. The convergence was not considered to be reached until the velocity and pressure at the back of the plate zone had been stabilized ${ }^{[32]}$. The boundary condition for inlet was velocity inlet with six levels $(0.1 \mathrm{~m} / \mathrm{s}, 0.5 \mathrm{~m} / \mathrm{s}, 1.0 \mathrm{~m} / \mathrm{s}, 1.5 \mathrm{~m} / \mathrm{s}, 2.0 \mathrm{~m} / \mathrm{s}$ and $2.5 \mathrm{~m} / \mathrm{s})$, and for outlet was pressure outlet with zero static pressure. The lateral surfaces of the virtual wind tunnel and chain plate were set as no-slip wall boundary conditions.

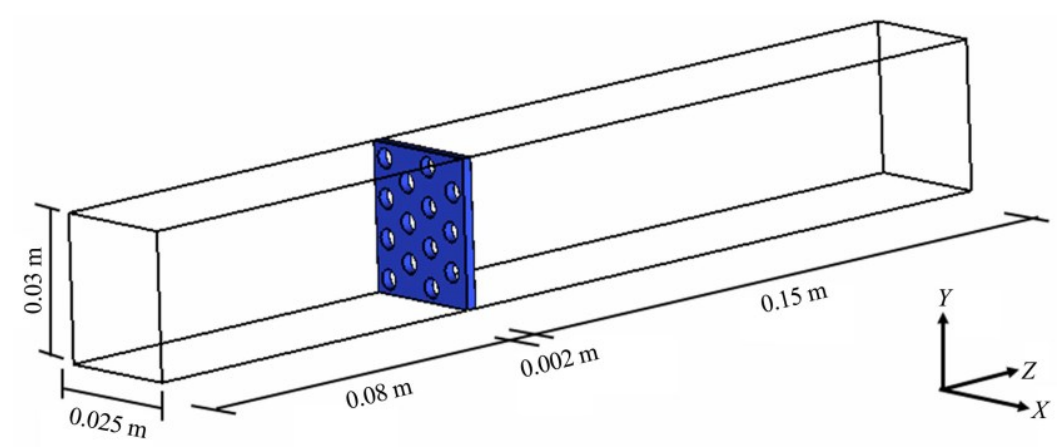

a. Geometry of virtual wind tunnel with chain plate 


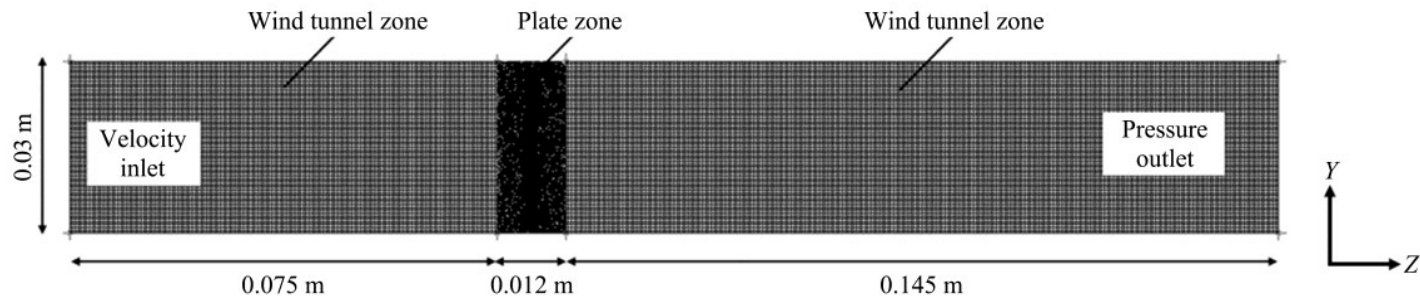

b. Vertical view of volume mesh along the middle horizontal plane of the CFD domain

Figure 2 Schematic diagram of geometry of virtual wind tunnel with chain plate (a) and vertical view of volume mesh along the middle horizontal plane of the CFD domain (b)

\subsection{Model validation}

The simulation model was validated by comparing air speed in the reactor with simulated values at the same points. The air speed in the reactor was measured by an anemometer, and simulated values were calculated by the model.

\subsubsection{Measurement of air speed}

As the bulk density of the compost pile was relatively stable during the cooling period, a lab experiment was conducted on the 9th day of compost. During the measurement, the aeration system remained aerated and the stirring plates stopped working. Air velocities (Testo 480) of 28 and 30 points in the reactor were measured with and without pile, respectively. Each point was measured for $10 \mathrm{~min}$. 28 measurement points were located at the bottom of the reactor, and in planes of $x=1.6 \mathrm{~m}, 2.2 \mathrm{~m}, 2.8 \mathrm{~m}$ and $3.4 \mathrm{~m}$, respectively. The detailed positions and coordinate values were illustrated in Table 2. Velocity in the empty reactor was also measured to evaluate the airflow field. Aeration volume was the same with the compost experiment $\left(32.5 \mathrm{~m}^{3} / \mathrm{h}\right)$. 30 measurement points were far away from the front elevation, and were situated at planes of $x=1.25 \mathrm{~m}, 1.85 \mathrm{~m}, 2.45 \mathrm{~m}, 3.05 \mathrm{~m}$, and $3.65 \mathrm{~m}$, respectively. The specific locations and coordinate values were illustrated in Table 3

\subsubsection{Simulation of air speed in the reactor}

Mesh of compost model was generated in ICEM CFD, Fluent (ver 17.0, ANSYS Inc., Pennsylvania, USA), and was adopted to discretize as well as solve the governing equations. The velocities of two points in the compost zone and area-weighted average velocity in the plane of the compost zone were monitored to estimate the convergence situation. When the curves of velocities were stabilized, convergence was regarded to be reached.

Table 2 Coordinate of measurement points in the reactor with compost pile

\begin{tabular}{cccc||cccc}
\hline Point No & $X / \mathrm{m}$ & $Y / \mathrm{m}$ & $Z / \mathrm{m}$ & Point No & $X / \mathrm{m}$ & $Y / \mathrm{m}$ & $Z / \mathrm{m}$ \\
\hline 1 & 1.6 & 0.50 & 0.10 & 15 & 2.8 & 0.50 & 0.10 \\
2 & 1.6 & 0.65 & 0.10 & 16 & 2.8 & 0.65 & 0.10 \\
3 & 1.6 & 0.65 & 0.15 & 17 & 2.8 & 0.65 & 0.15 \\
4 & 1.6 & 0.65 & 0.20 & 18 & 2.8 & 0.65 & 0.20 \\
5 & 1.6 & 0.78 & 0.10 & 19 & 2.8 & 0.78 & 0.10 \\
6 & 1.6 & 0.78 & 0.15 & 20 & 2.8 & 0.78 & 0.15 \\
7 & 1.6 & 0.78 & 0.20 & 21 & 2.8 & 0.78 & 0.20 \\
8 & 2.2 & 0.50 & 0.10 & 22 & 3.4 & 0.50 & 0.10 \\
9 & 2.2 & 0.65 & 0.10 & 23 & 3.4 & 0.65 & 0.10 \\
10 & 2.2 & 0.65 & 0.15 & 24 & 3.4 & 0.65 & 0.15 \\
11 & 2.2 & 0.65 & 0.20 & 25 & 3.4 & 0.65 & 0.20 \\
12 & 2.2 & 0.78 & 0.10 & 26 & 3.4 & 0.78 & 0.10 \\
13 & 2.2 & 0.78 & 0.15 & 27 & 3.4 & 0.78 & 0.15 \\
14 & 2.2 & 0.78 & 0.20 & 28 & 3.4 & 0.78 & 0.20 \\
\hline
\end{tabular}

Table 3 Coordinate of measurement points in reactor without compost pile

\begin{tabular}{cccc|cccc}
\hline Point No & $X / \mathrm{m}$ & $Y / \mathrm{m}$ & $Z / \mathrm{m}$ & Point No & $X / \mathrm{m}$ & $Y / \mathrm{m}$ & $Z / \mathrm{m}$ \\
\hline 1 & 1.25 & 0.50 & 0.30 & 16 & 2.45 & 0.78 & 0.30 \\
2 & 1.25 & 0.65 & 0.30 & 17 & 2.45 & 0.78 & 0.55 \\
3 & 1.25 & 0.65 & 0.40 & 18 & 2.45 & 0.78 & 0.85 \\
4 & 1.25 & 0.78 & 0.30 & 19 & 3.05 & 0.50 & 0.30 \\
5 & 1.25 & 0.78 & 0.55 & 20 & 3.05 & 0.65 & 0.30 \\
6 & 1.25 & 0.78 & 0.85 & 21 & 3.05 & 0.65 & 0.40 \\
7 & 1.85 & 0.50 & 0.30 & 22 & 3.05 & 0.78 & 0.30 \\
8 & 1.85 & 0.65 & 0.30 & 23 & 3.05 & 0.78 & 0.55 \\
9 & 1.85 & 0.65 & 0.40 & 24 & 3.05 & 0.78 & 0.85 \\
10 & 1.85 & 0.78 & 0.30 & 25 & 3.65 & 0.50 & 0.30 \\
11 & 1.85 & 0.78 & 0.55 & 26 & 3.65 & 0.65 & 0.30 \\
12 & 1.85 & 0.78 & 0.85 & 27 & 3.65 & 0.65 & 0.40 \\
13 & 2.45 & 0.50 & 0.30 & 28 & 3.65 & 0.78 & 0.30 \\
14 & 2.45 & 0.65 & 0.30 & 29 & 3.65 & 0.78 & 0.55 \\
15 & 2.45 & 0.65 & 0.40 & 30 & 3.65 & 0.78 & 0.85 \\
\hline
\end{tabular}

\subsection{Model application}

The model was used to evaluate the aeration performance of the existing system firstly. In view of the uneven airflow distribution in the existing reactor, this study researched the airflow field of increased pipe diameters with the simulation model. Since the original diameter was $0.013 \mathrm{~m}$, taking manufacturing technique into consideration, optimized diameters were $0.025 \mathrm{~m}$ and $0.04 \mathrm{~m}$. Apart from diameter, the size and number of holes in the pipe, spacing between adjacent holes, arrangement, and angle between two rows of the hole were the same as the existing pipe.

\section{Results and discussion}

\subsection{Boundary conditions}

3.1.1 Resistance coefficients of the compost pile

Unit weight of the pile: For different samples, the maximum and minimum weights of the dried pile were $15.9 \mathrm{~g}$ and $14.8 \mathrm{~g}$, respectively. The volume of the cutting ring was $100 \mathrm{~mL}$. Through Equation (4), the unit weight of pile at different samples ranged from 0.148 to $0.167 \mathrm{~g} / \mathrm{cm}^{3}$, respectively. The average unit weight of the pile was $0.157 \mathrm{~g} / \mathrm{cm}^{3}$. Specific values of all samples were revealed in Figure 3a.

The specific gravity of the pile: The pile weight was $14.6 \mathrm{~g}$. The specific gravity of kerosene was $0.82 \mathrm{~g} / \mathrm{cm}^{3}$; the total weight of kerosene of $100 \mathrm{~mL}$ was $82 \mathrm{~g}$. For different samples, the maximum and minimum weights of the mixture (pile and kerosene) of $100 \mathrm{~mL}$ were $78.1 \mathrm{~g}$ and $76.1 \mathrm{~g}$, respectively. Through Equation (5), the specific gravity of the pile of 36 samples ranged from 0.584 to $0.647 \mathrm{~g} / \mathrm{cm}^{3}$. The average specific gravity of the pile was $0.626 \mathrm{~g} / \mathrm{cm}^{3}$. Specific values of each sample were shown in Figure 3a. 
The void fraction of the pile: from Equation (7), the maximum and minimum void fraction of 36 measurement points were $77.1 \%$ and $71.4 \%$, respectively. The average void fraction was $75.0 \%$, and the maximum relative difference was $8.0 \%$. Specific values of 36 samples were illustrated in Figure $3 b$.

Mean particle diameter: The particle size distribution of the compost pile in one measurement sample is revealed in Table 4. The midpoint of particle size in this point was $D_{i}$ in Equation (8); the class frequency in this study was the weight of the compost pile in each class. Since the maximum size of the particle in the experiment was less than $30 \mathrm{~mm}$, the upper limit value of class 8 was set to $30 \mathrm{~mm}$. Through Equation (8), the mean particle diameter of this point was $5.56 \mathrm{~mm}$. Measurement of other points was the same as the above. The maximum and minimum mean particle diameters of 36 points were 5.81 and $5.32 \mathrm{~mm}$, respectively. The mean diameter was $5.59 \mathrm{~mm}$, and the maximum relative difference was $8.7 \%$. Specific values of all samples were shown in Figure 3b.

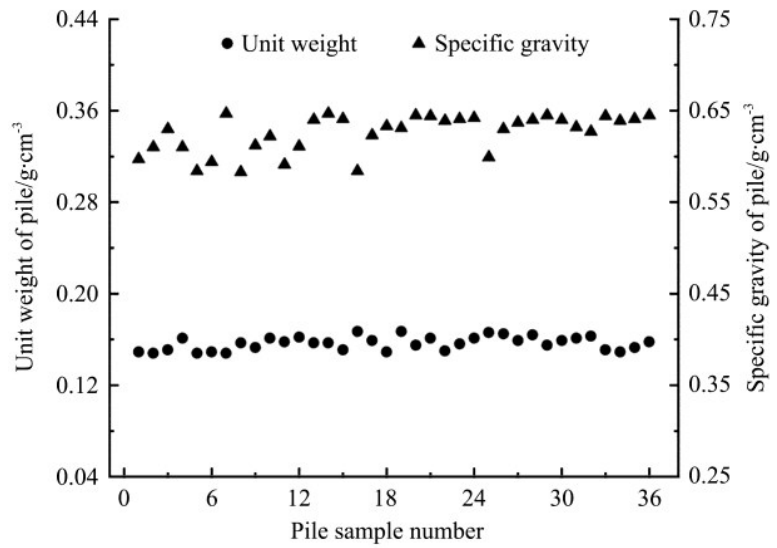

a. The unit weight and specific gravity

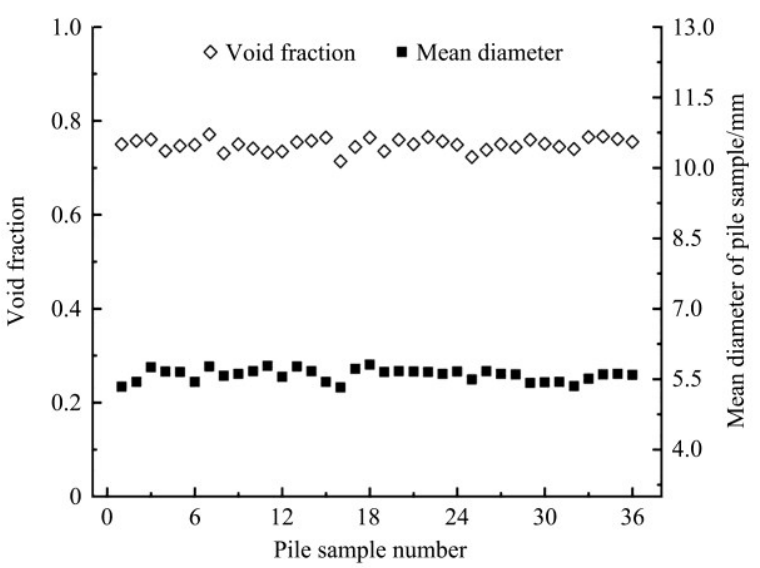

b. The void fraction and mean particle diameter of 36 the pile samples

Figure 3 Physical parameters of different pile samples

Table 4 Distribution of the pile particle size in one measurement point

\begin{tabular}{cccccc}
\hline $\begin{array}{c}\text { Class } \\
\text { No. }\end{array}$ & $\begin{array}{c}\text { Midpoint } \\
D_{i} / \mathrm{mm}\end{array}$ & $\begin{array}{c}\text { Range of } \\
\text { size/mm }\end{array}$ & $\begin{array}{c}\text { Frequency } \\
N_{i} / \mathrm{g}\end{array}$ & $\begin{array}{c}\text { Cumulative } \\
\text { frequency } \Sigma_{i} N_{i} / \mathrm{g}\end{array}$ & $\begin{array}{c}\text { Cumulative } \\
\text { fraction } \Sigma_{i} N_{i} / N\end{array}$ \\
\hline 1 & 0.125 & $0-0.25$ & 0.06 & 0.06 & 0.0026 \\
2 & 0.375 & $0.25-0.50$ & 0.46 & 0.52 & 0.023 \\
3 & 0.750 & $0.5-1.0$ & 2.09 & 2.61 & 0.114 \\
4 & 2 & $1-3$ & 4.75 & 7.36 & 0.321 \\
5 & 4 & $3-5$ & 3.22 & 10.58 & 0.462 \\
6 & 7.500 & $5-10$ & 3.07 & 13.65 & 0.596 \\
7 & 15 & $10-20$ & 6.34 & 19.99 & 0.873 \\
8 & 25 & $20-30$ & 2.91 & 22.90 & 1 \\
\hline
\end{tabular}

Resistance coefficients: The maximum relative difference of void fraction and mean particle diameter of the pile among all measurement points were within $10 \%$, which showed that it was feasible to treat the pile as homogeneous porous media. Through Equations (1)-(3), viscous and inertial resistance coefficients of the pile were $719424.46 \mathrm{~m}^{-2}$ and $373.03 \mathrm{~m}^{-1}$, respectively.

3.1.2 Resistance coefficients of the plate with CFD

When treating the chain plate as porous media, the regression relationship between inlet velocities and pressure drops per unit length was revealed in Figure 4. The regression equation was $\Delta P z / L z=0.93 v_{z}{ }^{2}+0.064 v_{z}$. Through Equation (9), viscous and inertial resistance coefficients of chain plate in $z$-direction (the thickness direction) were $3581.02 \mathrm{~m}^{-2}$ and $2.88 \mathrm{~m}^{-1}$, respectively.

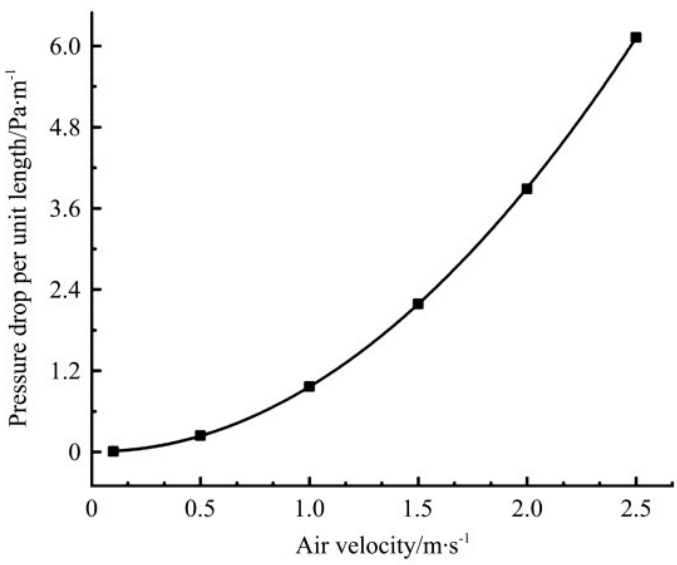

Note: The solid line was polynomial regression

Figure 4 Regression relationship between inlet velocities and pressure drops per unit length in $z$-direction

\subsection{Model validation}

When the reactor was filled with a compost pile, simulated and measured velocities are illustrated in Figure 5a. Reasonable agreements had been achieved between measured and simulated values, and the average relative error of all measured points was $9.1 \%$. The biggest discrepancies, as well as the standard deviation of the measured velocities, were observed at points 12 and 26, which were between two branch pipes, and near the plate as well as the wall of the reactor. It was caused by the complicated airflow. Air jetted into the reactor through holes in the pipe; two high-speed streams that had opposite directions converged at the middle of two adjacent branch pipes and then changed direction. As a result, the slight discrepancy between the planned and measured positions could result in a big difference concerning the velocity. The greatest relative difference was $13.8 \%$ at point 1 . As it was at aeration weak zone, the relative error was more significant although the absolute difference is not huge. A great difference existed in some individual points. However, all simulation values were within the variation range of measured values. Overall, the CFD model was proved to be reasonable and accurate for the simulation of airflow fields in piles.

Figure 5b shows the simulated and measured velocity in the reactor without pile. The average relative difference of 30 points was $6.9 \%$, the largest absolute difference appeared at points 16 and 28 , which were near the plate and wall of the reactor. It was contributed to the complex airflow. High-speed airflow entered reactor offset to the pipe; jetted along the surface; moved towards the outlet of the reactor (Figure 7c). Therefore a slight deviation of actual measurement points could result in a great difference in velocity. While the largest relative difference was $12.1 \%$, appearing at point 9 , it was also caused by the low velocity of 
measurement point in aeration weak zone. Consequently, the relative difference became more significant. Overall, all simulation values were within the deviation range of measured velocity magnitude, and the CFD model was certified to be reasonable for further systematic simulations and investigations.

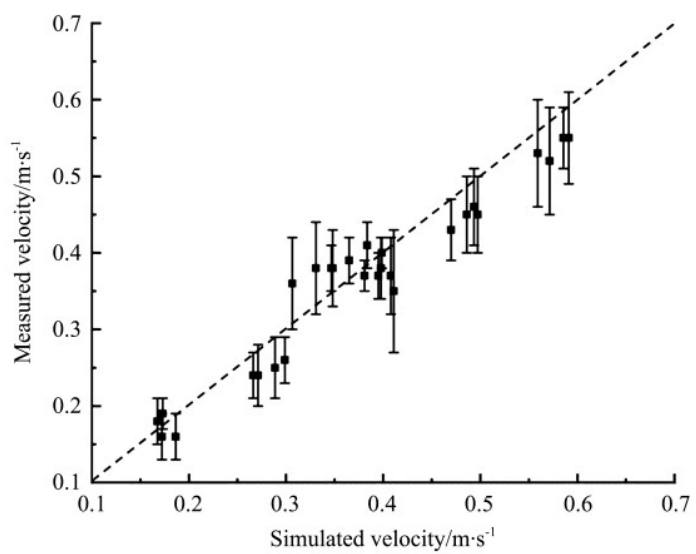

a. With pile

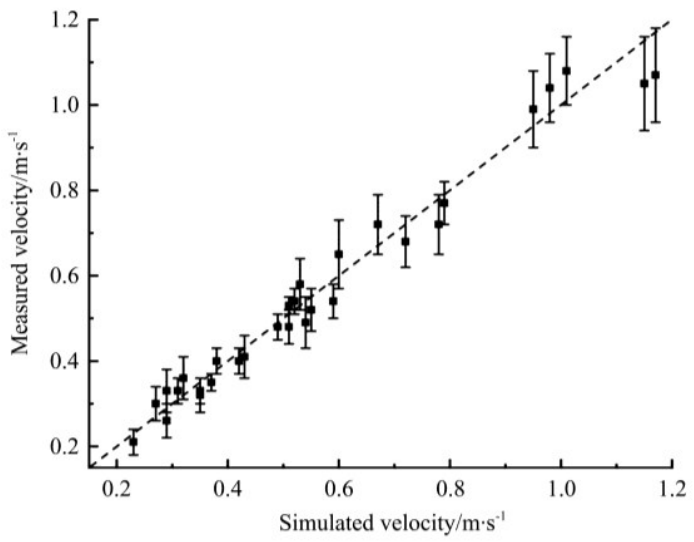

b. Without pile

Note: Vertical error bars indicate the standard deviation of replications of the field measurement at each location. Dashed lines represent the simulated results are exactly the same as the field measurement.

Figure 5 Comparison of simulated and measured velocity in the reactor with/without pile

\subsection{Evaluation of airflow in the reactor}

Figure $6 \mathrm{a}$ and $6 \mathrm{~b}$ show the velocity contour and streamlines in the reactor with pile at planes of $x=1.29 \mathrm{~m}$ and $2.17 \mathrm{~m}$, that was near the first branch pipe and between two adjacent pipes (Figure 1b), respectively. The figures showed uneven airflow distribution with vortex and weak zones. The reason was that the angle between pipe and inlet airflow was excessively small, inlet air was inclined to jet towards the rear end of the branch pipe, therefore a less circulated area occurred near the forepart of the pipe (Figure 6a). Simultaneously, since the air tended to move towards the less resistant area and the length of the branch pipe was shorter than the width of the reactor, at the rear end of the pipe, the air moved into free space beneath the pile firstly. Hence the airflow direction shown in Figure 6a was downwards. Figure $6 \mathrm{~b}$ also illustrates the non-uniform airflow distribution at the bottom of the reactor near the pipe, velocity at the rear end of the pipe was higher than in other regions.

Uniformity of the airflow distribution in the reactor and pile was evaluated with the turbulence intensity. It is defined as the ratio of the standard deviation to the mean, which reveals the extent of air speed variability in relation to the mean speed ${ }^{[37]}$. In the compost zone, the average turbulence intensity at planes of $x=$ $1.29 \mathrm{~m}$ and $x=2.17 \mathrm{~m}$ were 5.63 and 2.42 , respectively.

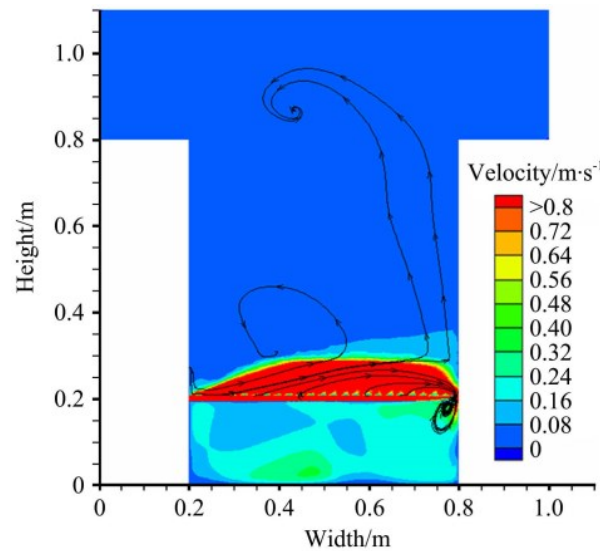

a. $x=1.29 \mathrm{~m}$ in the pile

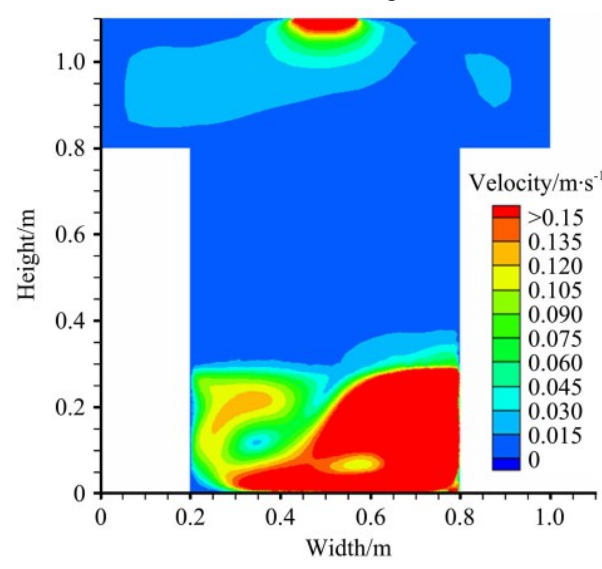

b. $x=2.17 \mathrm{~m}$ in the pile

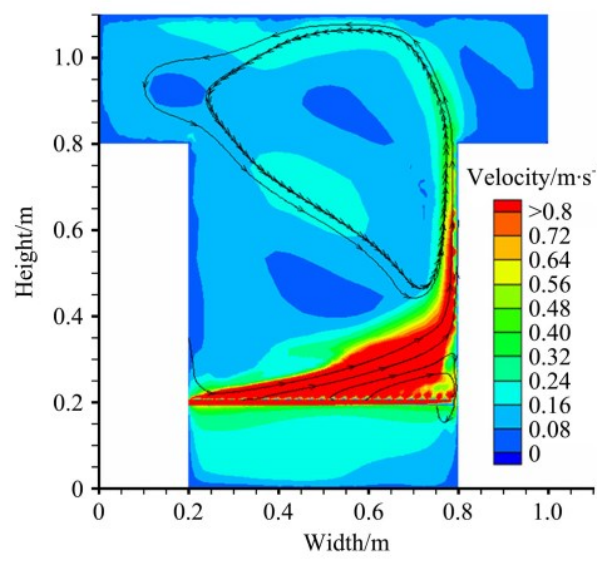

c. $x=1.29 \mathrm{~m}$ in reactor

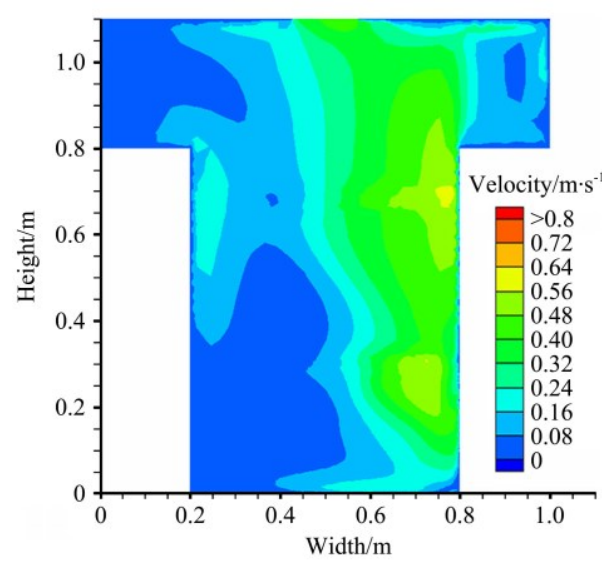

d. $x=2.17 \mathrm{~m}$ in reactor

Figure 6 Airflow streamlines and air speed distribution at planes of $x=1.29 \mathrm{~m}$ (a) and $x=2.17 \mathrm{~m}$ (b) in the pile and planes of $x=1.29 \mathrm{~m}$ (c) and $x=2.17 \mathrm{~m}(\mathrm{~d})$ in the reactor with a pipe diameter of $0.013 \mathrm{~m}$ 
Figure $6 \mathrm{c}$ and $6 \mathrm{~d}$ show the velocity contour and streamlines in the pile at planes of $x=1.29 \mathrm{~m}$ and $2.17 \mathrm{~m}$. Figure $6 \mathrm{c}$ shows that the inlet airflow moved towards the axis of the pipe, forming an adherent jet near the surface of the reactor, which resulted in a less circulated zone near the front end, and a vortex zone near the rear end of the pipe. The main reason was the diameter of the branch pipe was unreasonable, resulted in large velocity in the pipe. Since the direction of the inlet airflow was determined by the velocity in the pipe and the velocity generated by static pressure, when the static pressure provided by the fan was constant, the angle between inlet airflow and pipe axis decreased with the increased velocity in the pipe. Figure $6 \mathrm{~d}$ also illustrates that the velocity near the rear end of the pipe was larger than the forepart of the pipe. In compost zone, the average turbulence intensity at planes of $x=1.29 \mathrm{~m}$ and $x=2.17 \mathrm{~m}$ were 2.30 and 0.68 , respectively.

\subsection{Application of the CFD model}

3.4.1 Air speed distribution uniformity with different pipe diameters

Table 5 was turbulence intensity in the compost zone with different pipe diameters in the pile and reactor. In this work, the turbulence intensity in the compost zone was obtained based on the average turbulence intensity of four parallel planes of $x=1.29 \mathrm{~m}$, $x=2.17 \mathrm{~m}, x=3.08 \mathrm{~m}$, and $x=4 \mathrm{~m}$. It shows that the pipe diameter significantly affected the airflow distribution. With increased diameter, the average turbulence intensity descended. The maximum fluctuation range appeared at pipe diameter of $0.4 \mathrm{~m}$, with the turbulence intensity decreasing from 3.57 to 1.54 in the pile and reducing from 1.43 to 0.42 in the reactor, which implied the aeration performance of diameter of $0.04 \mathrm{~m}$ was superior to it of 0.013 and $0.025 \mathrm{~m}$. The appropriate diameter was beneficial to increasing airflow distribution uniformity in the pile and reactor. Additionally, the turbulence intensity of the reactor with pile was higher than it without pile.

Table 5 Turbulence intensity in compost zone at different pipe diameters in the pile and reactor

\begin{tabular}{|c|c|c|c|c|c|c|}
\hline \multirow{2}{*}{\multicolumn{2}{|c|}{$\begin{array}{l}\text { Pipe diameter } \\
\qquad / \mathrm{m}\end{array}$}} & \multicolumn{4}{|c|}{ Turbulence intensity at different planes } & \multirow{2}{*}{$\begin{array}{c}\text { Average } \\
\text { turbulence } \\
\text { intensity in } \\
\text { compost zone }\end{array}$} \\
\hline & & $x=1.29 \mathrm{~m}$ & $x=2.17 \mathrm{~m}$ & $x=3.08 \mathrm{~m}$ & $x=4.00 \mathrm{~m}$ & \\
\hline \multirow{3}{*}{ In the pile } & 0.013 & 5.63 & 2.42 & 4.86 & 1.37 & 3.57 \\
\hline & 0.025 & 3.51 & 1.15 & 3.57 & 0.89 & 2.28 \\
\hline & 0.040 & 2.37 & 0.56 & 2.68 & 0.57 & 1.54 \\
\hline \multirow{3}{*}{ In reactor } & 0.013 & 2.3 & 0.68 & 1.95 & 0.75 & 1.43 \\
\hline & 0.025 & 1.1 & 0.45 & 1.07 & 0.46 & 0.77 \\
\hline & 0.040 & 0.5 & 0.31 & 0.59 & 0.28 & 0.42 \\
\hline
\end{tabular}

3.4.2 Airflow field in the pile and in reactor with increased pipe diameter

Since the airflow distribution with the pipe diameter of $0.04 \mathrm{~m}$ was the most optimized among different diameters, Figure 7 shows the airflow streamlines and distribution at planes of $x=1.27 \mathrm{~m}$ and $x=2.17 \mathrm{~m}$ in the pile with the pipe diameter of $0.04 \mathrm{~m}$. The inlet airflow moved to the top of the reactor directly instead of firstly towards the wall of the reactor, and then the uniformity of the airflow distribution increased significantly. Compared with Figure $6 \mathrm{a}$, the vortex and aeration weak zone reduced. The main reason was that under the condition of the constant inlet air volume and total pressure, the velocity in the pipe reduced with the increased pipe diameter, and therefore the angle between inlet air and duct increased, which resulted in the increased velocity in the reactor near the front end of the pipe. Figure $7 \mathrm{~b}$ also illustrates the improvement of airflow distribution uniformity at the plane of $x=2.17 \mathrm{~m}$, which was between two adjacent pipes.

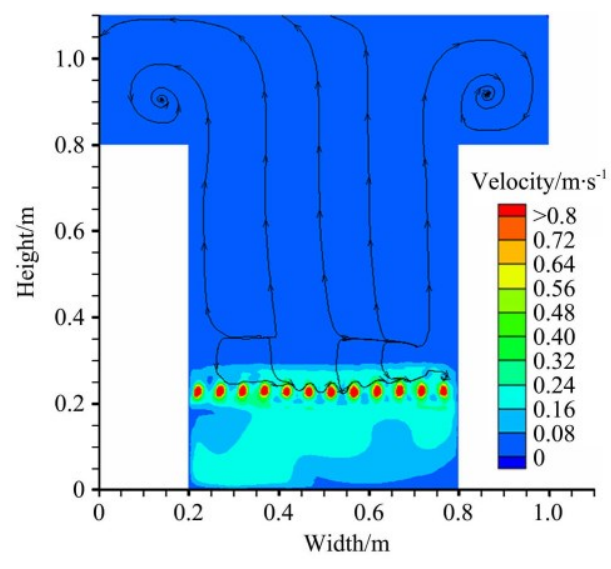

a. $x=1.29 \mathrm{~m}$ in the pile

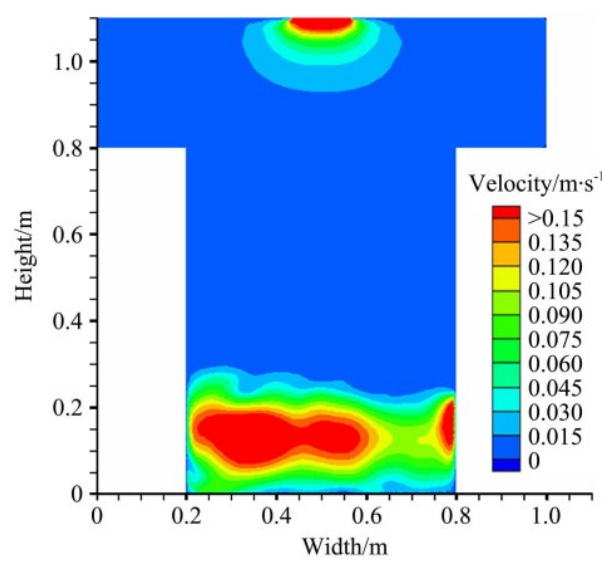

b. $x=2.17 \mathrm{~m}$ in the pile

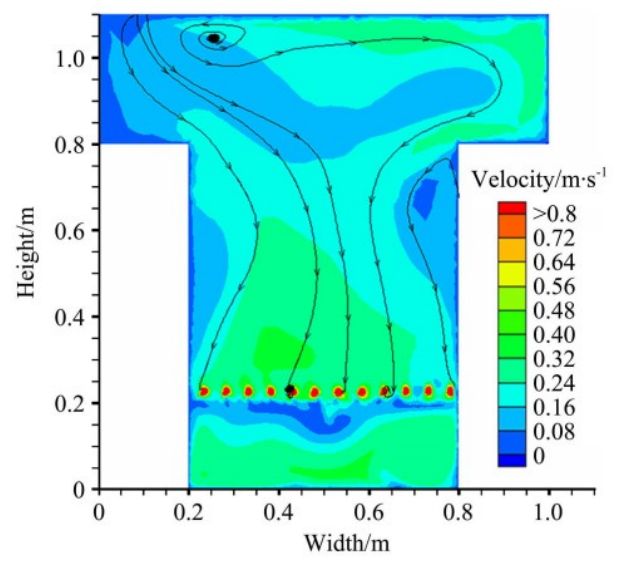

c. $x=1.29 \mathrm{~m}$ in reactor

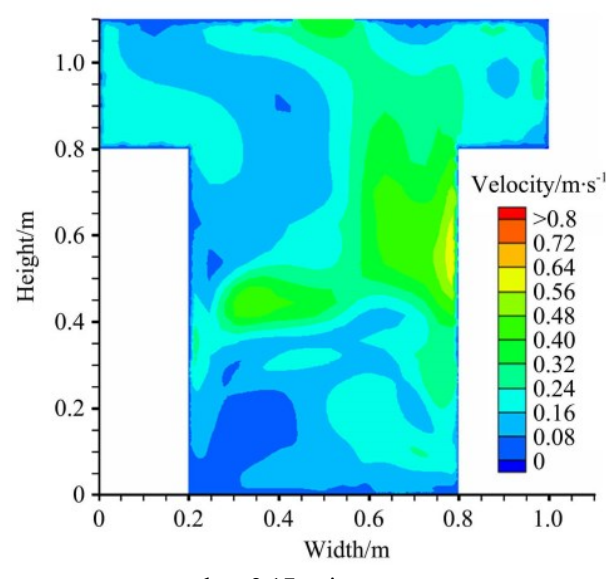

d. $x=2.17 \mathrm{~m}$ in reactor

Figure 7 Airflow streamlines and distribution at planes of $x=$ $1.29 \mathrm{~m}$ (a) and $x=2.17 \mathrm{~m}$ (b) in the pile and at planes of $x=1.29 \mathrm{~m}$ (c) and $x=2.17 \mathrm{~m}(\mathrm{~d})$ in reactor with pipe diameter of $0.04 \mathrm{~m}$ 
Figures $7 \mathrm{c}$ and $7 \mathrm{~d}$ indicate the airflow pattern at planes of $x=1.27 \mathrm{~m}$ and $x=2.17 \mathrm{~m}$ in the reactor. Compared with Figure 6c, the aeration weak zone reduced significantly and the airflow was more evenly distributed in the reactor, but the velocity in the reactor near the forepart of the pipe was still higher than it in rest areas. The aeration weak zone in Figure $7 \mathrm{~d}$ descended as well. Similarly, the amelioration of airflow distribution was ascribed to the increased diameter of the pipe.

\section{Conclusions}

A three-dimensional CFD model was developed to simulate the airflow field in the pile and the reactor. The model was validated by the field experiment, then it was applied to simulate the aeration performance with increased pipe diameter. The following conclusions can be drawn:

1) Reasonable agreements were found between the measured and simulated air speed in the pile and reactor (the relative differences were within 10\%). The CFD model that adopted unstructured mesh, employed standard k- $\varepsilon$ model and SIMPLE scheme was certified to be reasonable to research the airflow field in compost pile and reactor.

2) For boundary conditions in the CFD model, it was feasible to treat the pile as the homogeneous porous media, as the maximum relative difference of void fraction and mean particle diameter of the pile among 36 samples were not significant (less than 10\%).

3) The pipe diameter had a significant effect on the airflow field in the pile and reactor. Appropriate diameter (increased from $0.013 \mathrm{~m}$ to $0.04 \mathrm{~m}$ ) can effectively optimize the uniformity of airflow distribution.

\section{Acknowledgements}

The project acknowledges that this work was financially supported by the Open Project of Key Laboratory of Ministry of Agriculture and Rural Affairs (KLTMCUAR2020-3). The authors also thank editors and reviewers for the fruitful discussion and useful comments.

\section{Nomenclature}

\begin{tabular}{cl} 
CFD & Computational fluid dynamics \\
$\alpha$ & Permeability of pile, $\mathrm{m}^{2}$ \\
$D_{p}$ & Mean particle diameter of pile, $\mathrm{m}$ \\
$\varepsilon$ & Void fraction of pile, $\%$ \\
$C_{v p}$ & Viscous resistance coefficient of pile, $\mathrm{m}^{-2}$ \\
$C_{I p}$ & Inertial resistance coefficient of pile, $\mathrm{m}^{-1}$ \\
$\gamma_{p}$ & Unit weight of pile, $\mathrm{g} \cdot \mathrm{cm}^{-3}$ \\
$\rho_{w}$ & Density of purified water, $\mathrm{g} \cdot \mathrm{cm}^{-3}$ \\
$G_{p}$ & Specific gravity of pile \\
$M_{c p}$ & Total weight of cutting ring and dried pile, $\mathrm{g}$ \\
$M_{c}$ & Weight of cutting ring, $\mathrm{g}$ \\
$V_{c}$ & Volume of cutting ring, $\mathrm{cm}^{3}$ \\
$M_{b p}$ & Total weight of pycnometer and dried pile, $\mathrm{g}$ \\
$M_{b}$ & Weight of pycnometer, $\mathrm{g}$ \\
$M_{b y}$ & Total weight of pycnometer and neutral liquids, $\mathrm{g}$ \\
$M_{b y p}$ & Total weight of pycnometer, neutral liquids and dried pile, $\mathrm{g}$ \\
$G_{y T}$ & Specific gravity of neutral liquids at $T^{\circ} \mathrm{C}$ \\
$V_{p}$ & Volume of pycnometer, $\mathrm{cm}^{3}$ \\
$D_{p}$ & Mean particle diameter of pile, mm \\
$n i$ & Class frequency \\
$D_{i}$ & Midpoint of the $i$-th interval, mm \\
\hline &
\end{tabular}

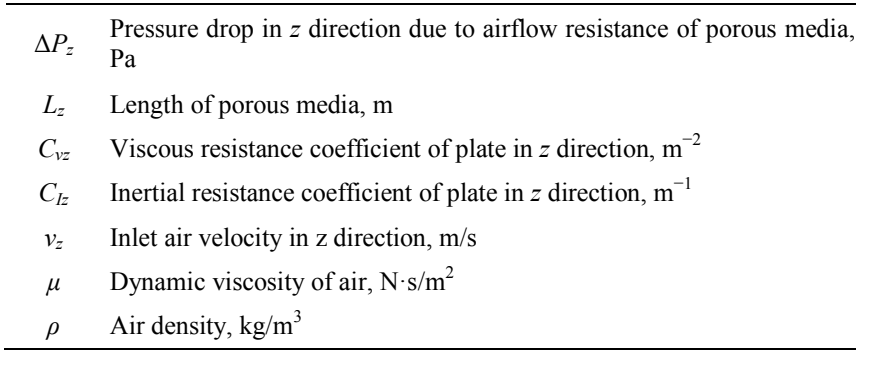

\section{[References]}

[1] Ministry of Agriculture and Rural Affairs. Being responsibe for promoting the green development of animal husbandry, 2018; Available from: http://www.moa.gov.cn/xw/zwdt/201805/t20180529_6147860.htm.

[2] Rao J R, Watabe M, Stewart T A, Millar B C, Moore J E. Pelleted organo-mineral fertilisers from composted pig slurry solids, animal wastes and spent mushroom compost for amenity grasslands. Waste Management, 2007; 27(9): 1117-1128.

[3] Sato A, Takeda H, Oyanagi W, Nishihara E, Murakami M. Reduction of cadmium uptake in spinach (Spinacia oleracea L.) by soil amendment with animal waste compost. Journal of Hazardous Materials, 2010; 181(1-3): 298-304.

[4] Horne J, Scholes P, Areikin E, Brown B. A survey of the UK organics recycling industry in 2012. WRAP. Banbury: WRAP, 2013.

[5] EPA U. Targeted national sewage sludge survey sampling and analysis technical report. Washington, DC: US Environmental Protection Agency Office of Water, 2009.

[6] Ding F, He Z, Liu S, Zhang S, Zhao F, Li Q, et al. Heavy metals in composts of China: historical changes, regional variation, and potential impact on soil quality. Environmental Science and Pollution Research, 2017; 24(3): 3194-3209.

[7] Bernal M P, Alburquerque J A, Moral R. Composting of animal manures and chemical criteria for compost maturity assessment. A review. Bioresource Technology, 2009; 100(22): 5444-5453.

[8] Guo R, Li G, Jiang T, Schuchardt F, Chen T, Zhao Y, et al. Effect of aeration rate, $\mathrm{C} / \mathrm{N}$ ratio and moisture content on the stability and maturity of compost. Bioresource Technology, 2012; 112: 171-178.

[9] Cayuela M L, Sánchez-Monedero M A, Roig A. Evaluation of two different aeration systems for composting two-phase olive mill wastes. Process Biochemistry, 2006; 41(3): 616-623.

[10] Yu S, Grant C, Jerry L. Airflow measurement in passively aerated compost. Canadian Biosystems Engineering, 2005; 47(6): 39-45.

[11] Gao M, Li B, Yu A, Liang F, Yang L, Sun Y. The effect of aeration rate on forced-aeration composting of chicken manure and sawdust. Bioresource Technology, 2010; 101(6): 1899-1903.

[12] Yuan J, Chadwick D, Zhang D, Li G, Chen S, Luo W. Effects of aeration rate on maturity and gaseous emissions during sewage sludge composting. Waste Management, 2016; 56: 403-410.

[13] Cerda A, Artola A, Font X, Barrena R, Gea T, Sánchez A. Composting of food wastes: status and challenges. Bioresource Technology, 2018; 248: 57-67.

[14] Zeng J, Shen X, Han L, Huang G. Dynamics of oxygen supply and consumption during mainstream large-scale composting in China. Bioresource Technology, 2016; 220: 104-109.

[15] Poulsen T G. Temperature, pressure and air flow distribution in passively aerated compost piles. Compost Science \& Utilization, 2010; 18(2): 127-134.

[16] Yoon N, Piette M A, Han J M, Wu W, Malkawi A. Optimization of Wind Positions for Wind-Driven Natural Ventilation Performance. Energies, 2020; 13(10): 2464-2488.

[17] Gresch M, Armbruster M, Braun D, Gujer W. Effects of aeration patterns on the flow field in wastewater aeration tanks. Water Research, 2011; 45(2): 810-818.

[18] Yang Y, Yang J, Zuo J, Li Y, He S, Yang X, et al. Study on two operating conditions of a full-scale oxidation ditch for optimization of energy consumption and effluent quality by using CFD model. Water Research, 2011; 45(11): 3439-3452.

[19] Bhuyar L, Thakre S, Ingole N. Design characteristics of curved blade aerator wrt aeration efficiency and overall oxygen transfer coefficient and comparison with CFD modeling. International Journal of Engineering, Science and Technology, 2009; 1(1): 1-15. 
[20] Xu N, Fan L, Pang H, Shi H. Feasibility study and CFD - aided design for a new type oxidation ditch based on airlift circulation. The Canadian Journal of Chemical Engineering, 2010; 88(5): 728-741.

[21] Martí-Herrero J, Alvarez R, Rojas M R, Aliaga L, Céspedes R, Carbonell J. Improvement through low cost biofilm carrier in anaerobic tubular digestion in cold climate regions. Bioresource Technology, 2014; 167(169): 87-93.

[22] $\mathrm{Wu}$ B. CFD prediction of mixing time in anaerobic digesters. Transactions of the ASABE, 2010; 53(2): 553-563.

[23] Dapelo D, Bridgeman J. Assessment of mixing quality in full-scale, biogas-mixed anaerobic digestion using CFD. Bioresource Technology, 2018; 265: 480-489.

[24] Seyedpour S M, Janmaleki M, Henning C, Sanati-Nezhad A, Ricken T. Contaminant transport in soil: A comparison of the theory of porous media approach with the microfluidic visualisation. Science of the Total Environment, 2019; 686: 1272-1281.

[25] Olatunde G, Atungulu G G, Sadaka S. CFD modeling of air flow distribution in rice bin storage system with different grain mass configurations. Biosystems Engineering, 2016; 151: 286-297.

[26] Qi W K, Guo, Y L, Xue M, Li Y Y. Hydraulic analysis of an upflow sand filter: tracer experiments, mathematical model and CFD computation. Chemical Engineering Science, 2013; 104: 460-472.

[27] Kichah A, Bournet P E, Migeon C, Boulard T. Measurement and CFD simulation of microclimate characteristics and transpiration of an Impatiens pot plant crop in a greenhouse. Biosystems Engineering, 2012; 112(1): $22-34$.

[28] Wu W, Zhai J, Zhang G, Nielsen P V. Evaluation of methods for determining air exchange rate in a naturally ventilated dairy cattle building with large openings using computational fluid dynamics (CFD). Atmospheric Environment, 2012; 63: 179-188.
[29] Cheng Q, Li H, Rong L, Feng X, Zhang G, Li B. Using CFD to assess the influence of ceiling deflector design on airflow distribution in hen house with tunnel ventilation. Computers and Electronics in Agriculture, 2018; 151: $165-174$

[30] Zambra C E, Moraga N O, Escudey M. Heat and mass transfer in unsaturated porous media: Moisture effects in compost piles self-heating. International Journal of Heat and Mass Transfer, 2011; 54(13-14): 2801-2810.

[31] Rong L, Nielsen P V, Bjerg B, Zhang G. Summary of best guidelines and validation of CFD modeling in livestock buildings to ensure prediction quality. Computers and Electronics in Agriculture, 2016; 121: 180-190.

[32] Cheng Q, Wu W, Li H, Zhang G, Li B. CFD study of the influence of laying hen geometry, distribution and weight on airflow resistance. Computers and Electronics in Agriculture, 2018; 144: 181-189.

[33] Wu W, Zhang G, Bjerg B, Nielsen P V. An assessment of a partial pit ventilation system to reduce emission under slatted floor-Part 2: Feasibility of CFD prediction using RANS turbulence models. Computers and Electronics in Agriculture, 2012; 83: 134-142.

[34] Chen T B, Luo W, Gao D, Zheng G D. Stratification of bulk density and its dynamics in the process of co-composting. Environmental Science, 2004; 25(5): 143-147.

[35] Cheng Q, Feng H, Meng H, Zhou H. CFD study of the effect of inlet position and flap on the airflow and temperature in a laying hen house in summer. Biosystems Engineering, 2021; 203(4): 109-123.

[36] Alderliesten M. Mean particle diameters. From statistical definition to physical understanding. Journal of Biopharmaceutical Statistics, 2005; 15(2): 295-325.

[37] Zhang Y, Kacira M, An L. A CFD study on improving air flow uniformity in indoor plant factory system. Biosystems Engineering, 2016; 147: 193-205. 